\title{
The Development and Construct Validation of a Spanish Version of an Academic Self-Concept Scale for Middle School Hispanic Students from Families of Low Socioeconomic Levels
}

\author{
Pete C. Menjares \\ Biola University
}

\author{
William B. Michael \\ University of Southern California
}

\author{
Robert Rueda \\ University of Southern California
}

\begin{abstract}
For at sample of 3056 th, 7 th. and 8th grade students, of whom $95 \%$ was from economically disadvantaged Hispanic families and for whom English was their second language, evidence was sought regarding the reliability and construct validity of scores on a Spanish version of an academic self-concept measure entitled Dimensions of Self-Concept (DOSC), comprising five subscales bearing the same names as those of the five hypothesized constructs that they were intended to operationalize: Level of Aspiration, Anxiety, Academic Interest and Satisfaction, Leadership and Initiative, and Identification versus Alienation. Reliability estimates varying between .72 and .80 were judged to be reasonably satisfactory. Results from oblique factor analysis lent empirical support for the hypothesized constructs of Anxiety, Leadership and Initiative, and ldentification versus Alienation. Scores associated with the subscales of Level of Aspiration and Academic Interest and Satisfaction generated a factor interpreted as a fusion of the two constructs of Level of Aspiration and Academic Interest and Satisfaction.

Key words: academic self-concept, construct validity, factor analysis, reliability
\end{abstract}

Con el fin de analizar la tiabilidad (como consistencia interna) y la validez de constructo de la versión en castellano de la escala Dimensiones del Auto-Concepto (DOSC). se empleó una muestra de 305 estudiantes de secundaria (grados 6, 7 y 8). El 95 por ciento de dicha muestra provenía de familias hispanas de bajo nivel socio-económico, en las que el inglés era la segunda lengua. La DOSC consta de cinco subescalas que se corresponden con los cinco constructos propuestos: Nivel de Aspiración, Ansiedad, Interés Académico y Satisfacción, Liderazgo e Iniciativa, e Identificación frente a Alienación. La fiabilidad, que varió entre .72 y .80 , se consideró satisfactoria. Los resultados del análisis factorial, utiilizando el método de rotación oblicua, apoyan empíricamente los constructos de Ansiedad, Liderazgo e Iniciativa, e Identificación frente a Alienación. Las puntuaciones asociadas con las subescalas de Nivel de Aspiración, e Interés Académico y Satisfacción, generaron un factor que se puede considerar como una fusión de estos dos constructos. Palabras clave: auto-estima académica, validez de constructo, análisis factorial, fiabilidad 
In a recent unpublished review of literature, Menjares (1995) found that self-concept is an important variable related to the academic performance of Hispanic students. The Hispanic population, which is quite diverse, is frequently differentiated by labels such as Latino, Mexican, Chicano, Cuban, Puerto Rican, Central American, Spanish, and Caribbean. The term "Hispanic" denotes many groups of different people (Chapa \& Valencia, 1993; Lampe, 1984; Moore \& Pachon, 1985). For this reason, the term Hispanic is to be used in a gencric sense in that it includes in this study children primarily from Mexico and secondarily from Central American and the Caribbean region.

In the educational setting, Byrne (1996), Hattic (1992), and Wylie (1974) have cited two issues on which research concerning the self-concept should focus: (a) the development of instruments affording valid and reliable scores and (b) attention to cross-cultural concerns in the development of self-concept measures. These two issues have become increasingly important in light of the substantial increase in immigrants in the United States during the last 10 to 15 years. The number of children in American public schools for whom English is their second language has grown markedly. As a result, questions regarding the most appropriate and best means for educating these students abound. Unfortunately, Hispanic students have continued to drop out of school at a rate higher than that of their Asian, African, and AngloAmerican peers. Conscquently, many variables have been studied to account for these drop-out data (Valencia, 1991).

To provide guidelines for teachers and counselors, both cognitive and affective measures presented in the first langunge of the students (Spanish, in the instance of students of Hispanic origin) can be expected to provide useful information. Specifically, in the affective domain, findings such as those reported in the literature have led to the development and further study of academic self-concept (Marsh, 1990; Marsh, Byrne \& Shavelson, 1988; Marsh, Walker, \& Debus, 1991; Michael \& Smith, 1976; Michael, Smith, \& Michael, 1978). Academic self-concept, whether used as an outcome itself or as a mediating variable that helps to explain achievement outcomes, is an important factor in education and in educational research (Byrne, 1984; Purkey, 1970).

To meet a deficiency in the availability of reliable and valid scores on academic self-concept instruments, Michael and Smith (1976) and Michael, Stnith, and Michael (1989) developed three forms of a scalc called the Dimensions of Self-Concept ( DOSC). This instrument was constructed to measure five non-cognitive factors associated with selfconcept in school settings. The five hypothesized dimensions (constructs) chosen by the authors to conceptualize the higher-order complex construct of Academic Self-Concept were: (a) Level of Aspiration (LOA), (b) Anxiety (ANX), (c) Academic lnterest and Satisfaction (AIAS), (d) Leaderihip and Initiative (IAI), and (e) Idenfification versus Alienation (lA). For each of these five constructs, at corresponding factor subscale of the DOSC bearing the same name as that of the construct was constructed. The three previously cited forms of the DOSC included the following: Form E for elementary school grades four, five, and six; Form $\mathrm{S}$, for secondary school grades seven through twelve; and Form $\mathrm{H}$ for college and university students (Michacl et al., 1989). Also, a form designed to be used with aduits in industrial or business settings was developed (Crowder \& Michael, 1989, 1991). More recently, translations into Arabic (Al-Samarrai, Michael, \& Hocevar, 1993), Portuguese (Villar, Michael, \& Gribbons, 1995), and Japancse (Patk \& Michael, 1999) have been prepared and validated.

The rationale or theoretical model underlying the development of the DOSC involved first the hypothesized construct of Level of Aspiration held by students in reference to their projected achievcment level-either too high or too low. Those students who set unrealistically high levels of aspiration might become discouraged and fearful (i.c., defined as the construct of Anxicty) conceming their loss of status in the eyes of significant others or of possible criticism reflecting a form of symbolic punishment. On the other hand, students choosing low level goals could receive temporary relief from the construct of Anxiety because they have been able to preserve a certain level of self- esteem but at the cost of subsequent development of positive attitudes toward learning. An optimal level of aspiration could lead to a minimal amount of anxiety and thus to acquisition of a sense of satisfaction of and interest in their school work-a circumstance reflecting the third construct of Academic Interest and Sutisfaction. Manifestation of this third construct could lead to creation of a fourth construct of Leadership and Initiative, associated with opportunities for leadership roles requiring initiative in the school setting. However, a lack of academic interest and satisfaction could lead to the students being overlooked for leadership roles. High standing in this fourth construct (Leadership and Initiative) could contribute to a student's acquiring positive feelings toward and identification with the school as an institution, whereas relatively low standing on this same construct could generate a sense of alienation or even feelings of hostility toward the institution-a fifth consiruct designated as Identification versus Alienation. Simply stated, frequent academic success and recognition lead to further success and a positive identification with the school as an instilution in which students feel happy and rewarded; repeated lack of success and minimal recognition for academic pursuits can be expected to result in feelings of frustration, indifference, alienation, and marked hostility toward the school and its values.

When the Spanish version of the DOSC, Form S, was developed, it was assumed, as implied earlier, that the same live dimensions that characterized a conceptualization of academic self-concept in American students would be comparable for students of largely Mexican descent and of similar age. Therefore, the same theoretical model for affectivity in school learning proposed by Michael and Smith (1976) was adopted for this study. 
Although measures such as the DOSC exist, their scores have not been validated for use with Hispanic learners of English as a second language. Therefore, it is hoped that this study may add to the growing body of research on the DOSC by developing the Spanish version and by obtaining evidence of the reliability and construct validity of its scores.

In an attempt to extend the research on the measurement of academic self-concept, the three primary purposes associated with this study were to: (a) describe the development of a Spanish version of a measure of academic self-concept (DOSC, Form $S$ ) intended for its use with children in grades 6 through 8 (ages 12 to 17 years); (b) determine estimates of internal-consistency of the scores of its 5 factor subscales; and (c) obtain evidence concerning whether each hypothesized construct associated with each of the 5 factor subscales received empirical support for a sample of Hispanic students in a middle school (i.e., a school for children in grades 6,7 , and 8 ).

A sclf-concept scale in Spanish that provides reliable and construct-valid scores can be administered to generate data which in turn may be used by teachers, school psychologists, and other school personnel to help identify students with potential problems in school and in adjustment early in their academic careers because of low self-concept often accompanied by high anxiety. The results arising from this investigation could also lead to a further clarification in the definition of academic self-concept itself. Another outcome of this inquiry would be that cross-cultural comparisons of the manifestation of the hypothesized constructs could be made in future studies.

\section{Method}

\section{Participants}

The subjects selected for this study $(N=305)$ were Hispanic adolescents (grades 6 through 8) of primarily Mexican descent. In this sample, there were 154 boys and 151 girls. These students were enrolled in a modified bilingual program in a large urban middle school located in the southeast part of a large metropolitan city. The school had a student enrollment of 3,500 with 165 certificated staff (tcachers licensed by the State of California as being eligible to instruct). This year-round school was one of the largest middle schools in the district with a student population which was $95 \%$ Hispanic.

The students were firs-gencration immigrants who varied in length of residence in the United States from less than one year to slightly over 10 years. These students were 11 $(n=57), 12(n=94), 13(n=103), 14(n=45)$, and $15(n$ $=6$ ) years of age. The average socioeconomic status of the families of the students was low (bottom 15\% of the general population) with a great number of the students (over 90\%) receiving Title 1 services, a program designed to assist students from economically disadvantaged families. Specifically, the per capita income for this community was the second lowest in California, and the percent of families living below the poverty level was the third highest in the state (Hall \& Gaquin, 1997). The community and school were also known for their high transience rate. In all, there were slightily over 1,600 limited English proficient (LEP) students enrolled in the Bilingual program of the school.

The students selected for this study were drawn from the English Language Development (ELD) program, which numbered from 500 to 600 students. In this ELD program, students received primary language instruction in the core subject-matter areas (Science, Mathematics, and Social Studies) and then studied English as a second language (ESL) in a two-hour block. These students were enrolled in one of three levels of ESL-Beginning, Intermediate, or Advanced levels. The students were assigned to one of these three ESL levels on the basis of their English language proficiency regardless of age or grade.

The students and classes selected for this study were typical of children in similar programs administered in other schools throughout this large southern California urban district. The students enrolled in this ELD program were the least English proficient and the least acculturated in the school. Also, only those students that returned a signed parent permission form to the school were allowed to participate in the study.

\section{Instrument}

Dimensions of Self-Concept Scale (DOSC, Form S; Michael \& Smith, 1976; Michael et al., 1989). The verbatim statements from the technical manual describing each of the DOSC factor subscales with the title corresponding to its hypothesized construct (Michael et al., 1989, p. 2) accompanied by two illustrative items are as follows:

Level of Aspiration (LOA). This dimension is a manifestation of patterns of behavior that portray the degree to which achievement levels and academic activities of students arc consistent with their perceptions of their potentialities in terms of scholastic aptitude or of past and current attainments. Sample items:

1. "I work hard to be among the best students in my classes" (Item 1).

2. "I refuse to give up on a difficult school assignment or task" (Item 16).

Anxiety $(A N X)$. This second dimension reflects behavior pattems and perceptions associated with emotional instability, a lack of objectivity, and a heightened or exaggerated concern about tests and the preservation of self-esteem in relation to academic performance.

Underlying this dimension is often a failure syndrome that indicates a marked discrepancy between the stabilized perception of what a student believes that he can achieve satisfactorily and his idealized perception of his expectations concerning what his teachers or parents maintain that he can do. This attitudinal pattern can become generalized to a self-concept indicative of feeling oneself to be an unworthy 
individual ridden with guilt with a possible need for selfpunishment or even self-destruction.

Sample items:

1. "I feel so nervous about some of my classes that it is hard for me to attend" (Item 7).

2. "Talking in front of the class makes me feel nervous" (Item 42).

Academic Interest and Satisfaction (AIAS). This third dimension portrays the sheer love of learning and pleasure gained by students in doing academic work and in studying new subject matter, an affective state much like that realized by the dedicated scholar who gains tremendous satisfaction in working in the library, in reading great books, in writing research papers, in conceptualizing new theories or explanations for observed phenomena-an intrinsic motivation involving learning for its own sake.

Sample items:

1. "I like to use the library to do reference work and special assignments" (Item 18).

2. "Some of my classes are so interesting that I do much more work than is required" (Item 33).

Leadership and Initiative ( $L A I)$. This fourth dimension appears to represent those behavior patterns and perceptions that are associated with star-like qualities, in which a student has an opportunity to demonstrate his mastery of knowledge, to help others, to give direction to group activities, to become the respected expert whom others consult, to put forth (hopefully diplomatically) sound suggestions for classroom activities reflecting the consensus of other students in a group, to exhibit a willingness to take the initiative in starting a project or assignment-either an individual or group endeavorand to follow it through to successful completion, and to take pride without display of conceit of one's capabilities to do a job quickly and well.

Sample items:

1. "Other students seek my advice or help in completing their assignments" (Item 14).

2. "I serve as the leader in many group projects and group activities" (ltem 34).

Identification vs. Alienation (IA). This fifth dimension is intended to represent the extent to which a student feels that he has been accepted as part of the academic community and has been regarded by his teachers and peers as a significant person who is respected for his own personal worth and integrity as a human being, in contrast to a feeling of being isolated or rejected in the academic environmenta feeling manifested by hostility toward the academic institution and its members-fellow students, teachers, counselors, administrators, and significant others; alienation embodies considerable resentment if not even defiance of regulations and rules of the school campus.

Sample items:

1. "I feel that I belong to and am a part of what is happening in class" (Item 40).

2. "Teachers listen to my ideas" (Item 70).

\section{Procedures}

Translation of the DOSC, Form $S$. The back-translation method, also referred to as the double translation technique (Marin \& Marín, 1991), was used in the translation of the DOSC into Spanish. This procedure had been employed with success in previous validation studies using the DOSC in its various forms (Al-Samarrai et al., 1993; Villar et al., 1995). The first cited author of this paper translated the DOSC into Spanish. It was subsequently revised by a bilingual/bicultural educator of Mexican descent who had earned degrees in Education and Psychology. A professor of Spanish who also had had teaching experience in secondary bilingual classrooms served as the back translator. The back translation underwent two revisions based upon the results of pilot tests. Bilingual teachers and the ESL coordinator for the sample used in this study provided numerous suggestions that were ultimately incorporated into the final translated version of the DOSC for secondary school students. The final Spanish version of the DOSC was considered to be as nearly equivalent as possible to the original English version.

Administration. Every effort was made to follow the instructions for the administration of the instrument in accordance with the directions provided in the technical and administrative manuals. As a result, the Spanish version of the DOSC, Form $S$, was administered in virtually the same manner as the English versions. The DOSC was intended to be a self-administering measure which required from 20 1040 minutes to complete.

All instructions to the students were presented in Spanish. The students werc made aware that the purpose of the items in the scale was to gencrate information that would be used by school personmel to help teachers be more sensitive to the needs and attitudes of their students. Also, the students were informed that (a) the questionnaires were not to be graded, (b) they were not taking a test, (c) the results would not affect their grades in the class, and (d) their complete and honest answers were very important. In a few instances, however; sludents were not able to complete all or part of the instrument because of their limited reading ability in Spanish.

The data were collected during the regularly scheduled ESL class of the students. During this two-hour block, students were given their usual six-minute break at the end of the first hour.

Scoring. The same scoring method used in the administration of the DOSC, Form $S$, in English was employed in the scoring of the Spanish version. The original DOSC, Form S, was developed in such a way as to limit the creation of a response set that could be associated with a particular factor. Therefore, every fifth item in the instrument corresponded to a particular factor subscale of the DOSC, Form S. Each of the items for the DOSC, Form $S$, contained five alternative answers: never, seldom, about half the time, very ofien, or always. These response choices were assigned differential scoring weights of $1,2,3,4$, or 
5, respectively. Negatively worded items were scored in reverse. As a result, the range of possible scores for each of the five 14-item factor subscales in the DOSC, Form $\mathrm{S}$, ranged from a minimum of 14 to a maximum of 70 points. Consequently, the higher a student's score on any of the factor subscales, the higher the degree of possession of the hypothesized construct associated with the subscale.

\section{Statistical analyses}

Once the data had been collected and scored, the data analysis followed the same statistical procedures and methods as those used by Al-Samarrai et al, (1993) and Villar et al. (1995) in the validation of scores on their translations of the DOSC, Form H (i.c., descriptive statistics, including means and standard deviations, and an exploratory oblique factor analysis). The following quantitative procedures were employed:

The mean and standard deviation for scores on each of the five factor subscales (LOA, ANX, AIAS LAI, and IA) were calculated. A coefficient alpha was found to indicate the level of internal-consistency reliability of scores on each factor subscale (sec Table 1).

An item analysis was performed by correlating scores on each item with: (a) total scores of the factor subscale of which it was a contributor (accompanied by a correction for spurious overlap), and (b) total scores on the remaining four factor subscales of which it was not a member (Michael et al., 1989; Paik \& Michael, 1999). A hil rate was computed by counting the number of times that the scores of an item were more highly correlated with the total scores of its own factor subscale than with the total scores of any one of the other four factor subscales. Both frequencics and percentages of hits were determined.

An oblique (oblimin) exploratory factor analysis (SPSS, 1990) was carried out on the correlation matrix of scores of 20 subtests or item parcels (four subtests for each factor subscale). The four subtests were constructed by selecting the first four, the next three, the following four, and the last three items in each of the factor subscales. Because of the relatively high degree of homogeneity of items within any one subscale, this selection procedure was essentially one of convenience, as there was no reason to believe that any one of the four subtests within a given factor subscale reflected a construct different from that in any other subtest within that same factor subscale. Scores on each of these four subtests were deternined and intercorrelated with the scores on all other subtests. The rationale central to the formation of such subtests was that a higher level of internal-consistency reliability of scores on the subtests of items would result than with scores on single items themselves (Michael et al., 1989; Paik \& Michacl, 1999). In the principal factor analysis procedure that was followed, five factor axes were rotated, consistent with the presence of five hypothesized constructs in the total scalc. An examination of the factor pattern of the coefficients, indicating the degree of association of each subtest with a rotated factor axis, was made in oblique solution for the sample of 305 respondents. Simultaneously, the matrix of intercorrelations of scores on both the five factor subscales and the 20 subtests (4 subtests per factor subscale) was examined to facilitate the psychological interpretation of the factors.

\section{Results}

\section{Internal-Consistency Estimates of Reliability for Scores on Each of the Five Subscales}

Estimates of internal-consistency of scores on the subscales (using alpha coefficient) are presented along the diagonal of Table 1. For the total sample of 305 students, scores on the Level of Aspiration (LOA), Anxiety (ANX), Academic Interest and Satisfaction (AIAS), Leadership and Initiative (LAI), and Identification vs. Alienation (IA) subscales yielded internalconsistency coefficients of $.77, .72, .75, .78$, and .80 , respectively. These coefficients were lower than those reported by Michael et al. (1989) for the English version but were comparable to those cited for younger samples. Although these coefficients were also lower than those found in previous studies where the DOSC was translated into a language other than English (Al-Samarrai et al., 1993; Villar et al., 1995), they were considered satisfactory.

Table 1

Means Standard Deviations, Alpha Coefficients, and lntercorrelations of Scores Among the Five-Factor Subscales of the $\operatorname{DOSC}(N=305)$

\begin{tabular}{lccccccc}
\hline DOSC Factor Subscales & 1 & 2 & 3 & 4 & 5 & $M$ & $S D$ \\
\hline 1. Level of Aspiration (LOA) & $(.77)$ & -.01 & .72 & .55 & .56 & 55.61 & 7.60 \\
2. Level of Anxiety (ANX) & & $(.72)$ & .05 & -.18 & -.13 & 40.81 & 9.00 \\
3. Academic Interest and Satisfaction (AIAS) & & & $(.75)$ & .63 & -.53 & 52.34 & 8.16 \\
4. Leadership and Initiative (LAI) & & & & $(.78)$ & .43 & 44.43 & 8.74 \\
5. Identification vs. Alienation (IA) & & & & & $(.80)$ & 56.46 & 8.39 \\
\hline
\end{tabular}

Note. Internal-consistency estimates or reljability of scores for the factor subscales are reported along the diagonal. 
A second approach to providing evidence of internalconsistency of scores within the factor subscales was to correlate the scores on each item in a given factor subscale with the total scores for the factor subscale of which it was a member as well as with the total scores for each of the remaining factor subscales. For the sample $(N=305)$, the frequencies of items that showed a higher correlation with the total scores on the 14-item factor subscale to which they supposedly belonged (corrected for spurious overtap) than with the total scores on any of the other subscales were 13 , $13,14,14$, and 14, respectively, for the LOA, ANX, AIAS, LAI, and IA factor subscales.

In short, for the 70 items of the DOSC scale, 68 out of the 70 items for the total sample registered the highest correlations with the total scores of their own intended subscale than with the total scores on any one of the remaining five subscales. Thus, a hit rate of $97 \%$ was obtained for the Spanish version of the DOSC, Form $S$. This finding was comparable to the results for the Arabic version (Al-Samarrai et al., 1993), which had a reported hit rate of 98.75\% (79 out of 80 items), and for the Portuguese version (Villar et al., 1995), which had reported a hit rate of $88.78 \%$ ( 71 out of 80 items) and $91.25 \%$ (73 out of 80 items) for females and males, respectively.

\section{Intercorrelations of Scores on the Five Factor Subscales}

Table 1 also presents the intercorrelations of the scores of the DOSC factor subscales. The three highest correlations of $.72, .63$, and .56 were associated with the pairings of the LOA and AIAS, AIAS and LAI, and LOA and IA factor subscales, respectively. The lowest correlations were obtained between scores on the ANX factor subscale and the scores on all other factor subscales. In addition, means and standard deviations of the scores on the five factor subscales are included in Table 1.

\section{Support for the Five Hypothesized Factors (Constructs) Based Upon Exploratory Factor Allalysis}

For the sample $(N=305)$, support was found for at least three of the five hypothesized factors, as observed in the higher loadings of the individual subtests on those factors to which they had been hypothesized to belong than on other factors. In this regard, the subtests of three or four items intended to represent a given factor showed higher loadings on that lactor than on any one of the other four remaining

Table 2

Pattern Matrix of 20 Subtests Based on Oblique Five-Factor Oblimin Solution

\begin{tabular}{|c|c|c|c|c|c|c|}
\hline \multirow{2}{*}{ Hypothesized Subscales } & \multirow{2}{*}{ Subtest Number } & \multicolumn{5}{|c|}{ Factors } \\
\hline & & 1 & 2 & 3 & 4 & 5 \\
\hline \multirow[t]{4}{*}{ Level of Aspiration (LOA) } & 4 & -.10 & -.03 & -.05 & -.80 & .06 \\
\hline & 3 & -.09 & .04 & -.09 & -.73 & -.07 \\
\hline & 2 & .05 & -.10 & -.05 & -.63 & -.08 \\
\hline & 1 & .44 & .10 & -.15 & -.09 & .06 \\
\hline \multirow[t]{4}{*}{ Level of Anxiety (ANX) } & 3 & -.06 & .72 & -.06 & .08 & .21 \\
\hline & 2 & -.19 & .68 & -.03 & -.05 & -.19 \\
\hline & 4 & .05 & .52 & .00 & -.15 & -.06 \\
\hline & 1 & .06 & .49 & .23 & .10 & -.03 \\
\hline \multirow[t]{4}{*}{ Academic Interest and Satisfaction (AIAS) } & 4 & .24 & .03 & .06 & -.56 & .15 \\
\hline & 3 & .13 & -.05 & -.06 & -.48 & -.27 \\
\hline & 1 & .32 & .10 & -.14 & --.25 & -.16 \\
\hline & 2 & .31 & .23 & -.15 & -.09 & -.42 \\
\hline \multirow[t]{4}{*}{ Leadership and Initiative (LAI) } & 2 & .76 & .03 & -.11 & .08 & -.06 \\
\hline & 4 & .67 & .10 & -.06 & -13 & .16 \\
\hline & 3 & .57 & -.15 & .06 & -.03 & -.10 \\
\hline & 1 & .43 & -.17 & -.04 & -.11 & -.10 \\
\hline \multirow[t]{4}{*}{ Identification vs. Alienation (IA) } & 4 & -.04 & -.08 & -.75 & -.07 & -.04 \\
\hline & 2 & .06 & .02 & -.73 & .01 & -.03 \\
\hline & $\mathbf{i}$ & .03 & -.02 & -.65 & .06 & .01 \\
\hline & 3 & .08 & .04 & -.59 & -.19 & .04 \\
\hline
\end{tabular}

Note. The percentages of varjance accounted for in the extraction of the first, second, third, fourth, and fifth factors were, respectively, $33.0,11.3,7.6,5.3$, and 4.3 , which resulted in a cumulative value of 61.5 . 
factors (as indicated by loadings across the rows of the factor matrix). Also, within each column, the loadings for a given set of four subtests that were intended to represent a hypothesized factor were higher than the loadings of all the remaining subtests in that column. The factors receiving this support were identified as ANX, LAI, and IA. The hypothesized LOA and AIAS factors tended to merge as a Fourth factor (a finding consistent with the correlation of .72 between scores on the LOA and AIAS factor subscales). The configuration of the factor loadings associated with the oblique solution appears in Table 2.

Passing mention should be made of the fact that the communality of a given test variable (which represents the proportion of variance of scores on each of the subtests, or item parcels, accounted for by the factors extracted) was relatively low. The communalities over the 15 subtests varied from .32 to .65 with a median value of .53 . These relatively low magnitudes of communality estimates would not be unexpected in view of the modest reliability levels obtained.

\section{Discussion}

In this section, an interpretation is made of the outcomes, largely in relation to the results that earlier studies have revealed concerning the DOSC. Reliability and validity issues constitute a primary focus of the discussion.

\section{Internal-Consistency Estimates of Reliability for Scores on Each of the Five Subscales}

The internal-consistency coefficients found in this study were lower than those reported in previous studies, where the DOSC was translated into a language other than English (Al-Samarrai et al., 1993; Villar et al., 1995), and lower than those cited in studies which used the English version as reported in the DOSC technical manual (Michael et al., 1989). The slightly lower internal-consistency reliability estimates reported for the Spanish version than for those found in other sludies with the DOSC might be attributed to a number of factors. It must be remembered that the sample in this study was one of children from homes reflecting low socioeconomic status. These children had poor reading skills in Spanish, though they were fluent Spanish speakers. Also, these students received little regular assistance with their academic work at home. That the students in this study were enrolled in a modified transitional bilingual program meant that instruction in their native language was progressively being reduced as instruction in English increased. Cummins (1989) made the distinction between communicative competence in a language as compared to academic ability in that language. One does not presume that communicating competently at an oral level necessarily implies ability to achieve in academic subjects. These students might have communicative abilities in Spanish, but not in academic Spanish or Spanish literacy. The Spanish translation of the DOSC, Form S, although prepared with these students in mind, might still have presented language that was above their present ability to comprehend. This situation might have also been evidenced by the fact that a number of the students sought assistance when reading the items or when they asked that the researcher read the items to them.

Also, the number of students needing assistance did not include those that required assistance but did not ask for it. The students in this sample appeared to be very eager not only to please their teachers and those conducting this study but also to give the impression that they were not in need of assistance in reading, even when they were not comprehending an item. Marín and Marín (1991) have cautioned against acquiescent responses and other potential problems when one interprets data for Hispanic samples. The extent to which student behaviors might have influenced these results needs further investigation.

\section{Intercorrelations of Scores on the Five Factor Subscales}

The results from Table 1 indicate that for the LOA, AIAS, LAI, and IA subscales, the intercorrelations of scores $(.43$ to .72$)$ were comparable to those $(.58$ to .76$)$ reported by Michael et al. (1989). The intercorrelations for the ANX factor subscale ranged between -.01 and .05 . The intercorrelations found in this investigation for ANX factor subscale scores were also comparable to those noted by Michacl et al. (1989), where the range of intercorrelations of scores for the ANX factor subscale was reported to be between -.02 and .24. As concluded by Michael et al. (1989), the factor subscales of LOA, AIAS, LAI, and IA might be reflecting a general factor facilitative of learning, whereas the ANX factor might be portraying a dimension that is either antithetical to or independent of the other four dimensions represented by the DOSC.

\section{Comparison of Scores of the Hispanic Sumple with those of Other Groups}

The means and standard deviations of factor subscale scores as found in this study were comparable to those reported by Michael et al. (1989). In fact, the means for this present sample were slightly higher than those found for the normative samples using the English version of the secondary form of the DOSC in the factor dimensions of LOA, AIAS, IA, and ANX. It was apparent that the means scores for this sample indicated that the students in the ELD program were comparable to (or higher than) the positive affect dimensions of self-concept as well as the anxiety dimension relative to those on whom the DOSC, Form S, had been normed. 
Because of the nature of the research design employed in this study, it was difficult to determine with certainty whether the findings reported added further support for the assumption that sccond language programs incorporating native language instruction have a positive impact upon the sel[-concept of students enrolled in them, as noted elsewhere (Coclho, 1981; Méndez, 1982; Wright \& Taylor, 1995). Additionally, it is difficult to establish whether this study has added further cvidence to support the assumption that native language instruction in a warm accepting environment reinforces the positive self-concept of its students (Méndez, 1982). However, it is clear from the findings that the sample in this study reccived slightly higher scores on the ANX factor subscale than did those reported in the norm group for the DOSC, Form $S$. Unfortunately, it was unclear regarding what might have contributed to this indication of slightly higher anxicty. It is conceivable that these scores were influenced by other sociocultural factors not accounted for in this study (Collier, 1995; Hawkes, Smith, \& Acredolo, 1980; Rogler, Cortes, \& Malgady, 1991; Williams \& Berry, 1991). Nevertheless, it must be noted that the slightly higher scores on the ANX factor subscale reported in this current study were well below the recommended level for concern reported by Michael et al. (1989) in their suggestions for counseling students.

\section{Support for the Five Hypothesized Factors Based on Exploratory Factor Analyses}

The results of this study yiedded only moderate support for the hypothesized constructs corresponding to the five factor subscales of the DOSC. Form $S$, for this sample. It was apparent from the results of the exploratory factor analysis that there was preliminary evidence to support a four-factor model of academic self-concept consisting of ANX, LAI, and IA factors, and a fourth factor comprising a fusion of dimensions hypothesized for the LOA and AIAS factor subscales. There might be other possible explanations for these findings.

In addition to the low level of reading skills mentioned previously, it is possible that these results were due to the fact that the students used for this study were younger than those who had participated in the development of the original English version of the DOSC, Form S. The original English version was developed to be administered to secondary students in grades seven to twelve (approximately ages 12 to 18 years). The students taking part in this study were in grades six to eight (ages 11 to 15 years). This difference in grade level and in corresponding age could be substantial when one considers that the students in this study were younger both cognitively and socially than those of previous samples.

The extent to which developmental factors contributed to an inability to establish a higher level of discriminant validity among the hypothesized factors as represented by scores in the five factor subscales of the DOSC, Form $S$, is unknown. However, it is conceivable that the students were unable to provide a more marked degree of differentiating between self-concept dinensions because of their relatively young age. Byrne's (1996) review of the literature made it clear that there is a tendency for the dimensionality of selfconcept to increase with age. Byrne also noted in her review that this expansion in self-concept dimensionality is most influential during the preadolescent and adolescent periods. These developmental periods were precisely those of the students in this sample.

Another lactor that should be taken into consideration when one is attompting to account for the multidimensionality of the academic self-concept subscales is the potential role of culture. Cornell, Delcourt, Goldberg, and Bland (1995) found that the same self-concept instrument administered to samples of White and Black gifted students in an elementary school setting yielded two different factor struclures, apparently because of cultural differences for each of the two groups. The findings were such that the authors suggested that measures of academic and social self-concept used with White students might not be applicable for minority students in gifted programs. Byrne (1996) also recommended that care be taken in the administration of self-concept measures for ethnic minorities and for those from low socioeconomic backgrounds.

In the present study, the LOA and ALAS factor subscales contained scores that were weighted on a fourth factor instead of on a fouth and a fifth factor, respectively. Both of these factor subscales (the scores of which were correlated .72) might be considered part of a "somewhat general factor that is facilitative of learning" (Michnel et al., 1989, p. 5). In this respect, they are similar in that they both facilitate learning.

Prcvious research with Hispanic samples has revealed that first-generation students have high academic aspirations, that they realize education is important, and that they know hard work is a significant aspect of upward mobility in American society (Kao \& Tienda, 1995; Suárez-Orozco \& Suárez-Orozco. 1995). These aspirations and related values are a reflection of the culture of the Hispanic immigrant. As a result, these students may be unable to manifest these two apparently highly correlated self-concept factors because they tend to view most of what they do in school as facilitative of learning. In other words, it is possible that LOA (Level of Aspiration) and AIAS (Academic Interest and Satisfaction) are very similar, if not causally related. However, this issue must be investigated further in order to detcrmine the degree to which cullure influences a student's response in this respect.

In summary, results of the exploratory (oblique) factor analysis to determine the factor structure and construct validity of the Spanish version of the DOSC. Form $S$, have partially confirmed the hypothesis that the outcomes of this present investigation were comparable to those found in previous studies for both the English and translated versions 
of the DOSC. Although lower than those of previous studies, the estimates of internal-consistency reliability for scores found for the Spanish version of the DOSC, Form S, were judged salisfactory. Also, the results of the item analysis lent support for the realization of a relatively high degree of internal-consistency of scores on the factor subscales on the Spanish version of the DOSC, Form S. The results of the intercorrelations, which were comparable to those of previous studies, also lent further support to the theory that scores in the LOA, AIAS, LAI, and IA factor subscales might be reflecting a gencral factor facilitative of learning, whereas scores in the ANX factor subscale might be portraying a factor that would be antithetical to or independent of the four other dimestsions (Michael el al., 1989).

However, the findings of this investigation did not provide complete support for the five hypothesized constructs corresponding to the five factor subscales for the English version. The writers suggest that limited reading ability in Spanish, low socioeconomic status, the age of the students, and cultural factors might have contributed to these results.

The profile that emerged from these data for students in an ELD program led to the inference that they were relatively high in academic self-concept and were slightly high in anxiety, as compared to the standing of previous samples on which the DOSC, Form $S$, had been normed. However, the scores for the ANX factor subscale were not dangerously high and were well below the level for concern. It is uncertain whether the warm and supportive environment of the ELD classroom might have contributed to high selfconcept, whereas sociocultural, language learning differences, and other factors not accounted for in this study might have contributed to the slightly high levels of anxicty.

\section{References}

A]-Samarrai, N., Michael. W.B., \& Hocevar, D. (1993). The development and validation of an Arabic version of an academic self-concept scale. Educational and Psychological Measurement, $53,249-257$.

Byme, B.M. (1984). The general acadenic self-concept nomological network: A review of construct validation research. Review of Educational Research, 55, 427-456.

Byrne, B.M. (1996). Measuring self-concept across the life span: Issues and instrumentation. Washington, DC: American Psychological Association.

Chapa, J., \& Valencia, R.R. (1993). Latino population growth. demographic characteristics, and educational stagnation: An examination of recent trends. Hispanic Joumal of Behavioral Sciences, 15, 165-187.

Coelho, A.D. (1981). Self-concept dimensions and linguistic profiles of urban preadolescents of Mexican descemt. Unpublished doctoral dissertation. Loyola University, Chicago.

Collier, V.P. (1995). Acquiring a second language for school. Directions in Language Education, $1,1-12$.
Cornell, D.G., Delcourt, M.A.B., Goldberg, M.D., \& Bland, L.C. (1995). Achicvement and self-concept of minority students in elementary school gifted programs. Journal for the Education of the Gifted, 18, 189-209.

Crowder, B. \& Michael, W.B. (1989). The measurcment of seltconcept in an employment seting. Educational and Psychological Measurement, 49, 421-428.

Crowder, B. \& Michael, W.B. (1991). The development and validation of a short form of a multidimensional self-concept measure for high technology employees. Educational and Psychological Meanurement, 57, 447-454.

Cunmins. J. (1989), Empowering minority students, Sacramento, CA: Califorma Association for Bilingual Education.

Hall, G.E., \& Gaquin, D.A. (Eds.). (1997). Coumty and city extra: Annual metro, city and county data book (6th ed.). Lanham, MD: Bernan Press.

Hattie, J.A. (1992). Self-concept. Hillsdale, NJ: Etlbaum.

Hawkes, G.R., Smith, J.. \& Acredolo, C. (1980). English language use among Mexican immigrants: A causative analysis. Hispanic Journal of Behaviorat Sciences, 2, 161-176.

Kao, G., \& Tienda, M. (1995). Optimism and achievement: The educational performance of immigrant youth. Social Science Quarterly, 76, 1-19.

Lampe, P.E. (1984). Mexican Americans: Labeling and mistabeling. Hispanic Joumal of Behavioral Sciences, 6, 77-85.

Marín, G., \& Marín, B.V. (1991). Research with Hispanic populations. Newbury Park, CA: Sage.

Marsh, H.W. (1990). The structure of academic self-concept: The Marsh/Shavelson model. Journal of Educational Psychology, $82,623-636$.

Marsh, H.W., Byrne. B.M., \& Shavelson, R.J. (1988). A multifaceted academic self-concept: Its hierarchical structure and its relation to academic achievement. Journal of Educational Psychology, 80, 366-380.

Marsh, H.W., Walker, R., \& Debus, R. (1991). Subject-specific components of academic self-concept and self-efficacy. Contemporary Educational Psychology, 16.331-345.

Méndez, G.I. (1982). Bilingual children's adaptation after a transitional bilingual education. Metas, 3, 1-99.

Menjares, P.C. (1995). How is self-concept related to the academic achievement of Hispantc students? A preliminary investigation and brief review of the liserature. Unpublished manuscript, University of Southern California.

Michael, W.B., \& Smith. R.A. (1976). The development and preliminary validation of three forms of a self-concept measure emphasizing school-related activities. Educational and Psychological Measurement, 36, 521-528.

Michael, W.B., Smith, R.A., \& Michael, J.J. (1978). Further development and valiciation of a self-concept measure involving school-related activities. Educational and Psychological Measurement, 38, 537-545.

Michael, W.B., Smith, R.A., \& Michael, J.J. (1989). Dimensions of Self-Concept (DOSC): A technical manual (Revised). San Diego, CA: Educational and Industrial Testing Service (Edl'TS). 
Moore, J., \& Pachon, H. (1985). Hispanics in the United States. Englewood Cliffs, NJ: Prentice-Hall,

Paik, C. \& Michael, W.B. (1999). A construct validity investigation of scores on a Japanese version of an academic self-concept scale for secondary school students. Educational and Psychological Measurement, 59, 98-110.

Purkey, W.W. (1970). Self-concept and academic achevenent. Englewood Cliffs, NJ: Prentice Hatl.

Rogler, L.H.. Cortes, D.E., \& Malgady, R.G. (1991). Acculturation and mental health status among Hispanics. Anterican Psychologist, 46, 585-597.

SPSS. (1990). SPSS for UNIX. Chicago, IL: SPSS.

Suárez-Oronco, C., \& Suárez-Orozco, M. (1995). Transfonnutions: Migration, family life, and achievement motivation among Latino adolescents. Stanford, CA: Stanford University Press.

Valencia. R.R. (Ed.). (1991). Chicano school failure and success: Research and policy agendas for the 1990s. London: Falmer Press.
Villar, I.D.A., Michael, W.B., \& Gribbons, B. (1995). The development and construct validation of a Portuguese version of an academic self-concept scale. Educational and Psychological Measurement, 55, 115-123.

Williams, C.L.. \& Berry. J.W. (1991). Primary prevention of acculturative stress among refugees: Application of psychological theory and practice. American Psychologist, 46, 632-641.

Wright, S.C., \& Taylor, D.M. (1995). Identity and the language of the classroom; Investigating the impact of heritage versus second language instruction on personal and collectjve selfesteem. Journal of Educational Psychology, 87, 241-252.

Wylie, R.C. (1974). The self-concept: A review of methodological considerations and measuring instrments. Lincoln, NE: Buros Institute of Mental Measurements.

Received October 22, 1998

Revision received October 26, 1999

Accepted November 23, 1999 